\title{
Management Theories Linking Individual and Organizational Level Analysis in Entrepreneurship Research
}

\author{
Linda Canina \\ Cornell University \\ Daniel Palacios \\ Technical University Valencia \\ Carlos Devece \\ University Jaume I
}

Final version published in International Entrepreneurship and Management Journal (2012), 8, $271-284$

L. Canina, Finance Faculty, School of Hotel Administration, Cornell University, Ithaca, NY, USA e-mail: $\underline{\text { lc29@cornell.edu }}$

D. Palacios, Department of Business Administration, Technical University Valencia, Valencia, Spain e-mail: dapamar@ doe.upv.es

C. Devece, Department of Business Administration and Marketing, University Jaume I, Castello de la Plana, Spain e-mail: device@emp.uji.es 


\begin{abstract}
This paper carries out a bibliographical review of the evolution of the individual level research, the new individual approaches and analyzes possible methods for the extension of entrepreneurship research to the organizational level. We also discuss about the suitability of the resource based view and network approaches. We review the management theories and paradigms which are capable of incorporating and linking individual and organizational level studies to the external context where entrepreneurs compete and seek opportunities. In this sense we refer to the resource based view and the network theory as they have been deemed the most adequate to incorporate micro level theories through a convergence of concepts, rather than by a combination or confrontation of ideas. The linking concepts of the individual and firm level theories are presented as an evolution of entrepreneurship research in a specific direction, showing the common ideas shared in the convergent point.
\end{abstract}

Keywords: Levels analysis, Management theories, Networks 


\section{Management Theories Linking Individual and Organizational Level Analysis in Entrepreneurship Research}

Entrepreneurship has been defined as "the creation of new economic activity" (Davidsson et al. 2006:27). It plays a key role in economic growth (Thurik and Wennekers 2004; van Stel 2006), creating jobs and driving innovation. This justifies the increased attention it receives by researchers, as reflected in the number of publications dealing with it (Welter and Lasch 2008); some of which focus exclusively on conceptual debates and research paradigms (Auerswald 2008; Westhead 2008). Low and MacMillan (1988), who define entrepreneurship as the creation of a new enterprise, focus on factors leading individuals or groups to start new organizations, or in other words, decisions to initiate entrepreneurial activity (van Stel 2006).

In accordance with this definition, the purpose of research in this field is to explore the role of entrepreneurs as relevant economic and social agents, as well as to explore ways in which their role in the economy may be enhanced. According to Low and MacMillan (1988) this definition implies studying entrepreneurship by means of a multi-level analysis (individual, organizational and aggregate level), for in order to grasp entrepreneurship in all its complexity, the relationships between these levels must be understood. These levels include a macroeconomic perspective, in which the aggregate actions of entrepreneurs' play a defining role in economic progress and microlevel analysis, taking the individual entrepreneur as the study unit.

Although entrepreneurs are individuals, they operate in an organizational (Shane and Venkataraman 2000), economic, social and institutional environment (Veciana and Urbano 2008), with their activity resulting in the creation of new businesses or the transformation and improvement of the already established ones. Different levels of study are, therefore, relevant. 
Macrolevel economic analysis suggests that certain institutional factors may explain the differences across countries in company creation rates. Microlevel analysis, on the other hand, emphasizes the entrepreneur's environment and particular set of circumstances.

The chief aim of this study is to review the management theories and paradigms which are capable of incorporating and linking individual and organizational level studies to the external context where entrepreneurs compete and seek opportunities. Two major approaches, the Resource Based View (RBV) and the network theory, have been deemed the most adequate to incorporate micro level theories through a convergence of concepts, rather than by a combination or confrontation of ideas. The linking concepts of the individual and firm level theories are presented as an evolution of entrepreneurship research in a specific direction, showing the common ideas shared in the convergent point.

The choice and definition of the analysis level is important, not only for the empirical design, but also for the selection and defensibility of the different theories used in entrepreneurship research. Traditionally, on each level specific theories and paradigms have been developed to tackle macroeconomic, organizational or individual questions. But because these levels are intimately intertwined (Davidsson and Wiklund 2001), results reached on any one level tend to be partial and limited. These reasons justified Low and MacMillan's call (1988) for an integration of the different levels in empirical research.

A study of Davidsson and Wiklund (2001) on levels of analysis in entrepreneurship research showed that the bulk of papers published in the most prestigious journals in the field used microlevel analysis (individual, team, firm), with a preponderance of the firm and individual level, and an increase in the joint level made up of "firm and individual". For Davidsson and Wiklund (2001), these results are explained by the systematic relationship 
established between the individual traits of the entrepreneurs and their firm's performance, as the mere description of the individuals that create and run firms has produced poor results. The trend detected by these authors has continued in the last decade, with an increase in the number of studies combining the description of the traits of individuals with that of the businesses they start and run.

This can be explained by the fact that entrepreneurship is always an interaction between entrepreneurial opportunities and enterprising individuals, and to neglect either of these factors is likely to yield unsatisfactory results. This integrative vision has led to new approaches, where the notion of entrepreneurship is incorporated into classical management theories in order to study entrepreneurship in a business context. These new approaches, such as Strategic Entrepreneurship or the Austrian Economic view of entrepreneurship (Chiles et al. 2010), born of the intersection of management and entrepreneurship (Schindehutte and Morris 2009), introduce the entrepreneur into a competitive environment, thus permitting the interaction between individual and firm levels to be analyzed. Nevertheless, the boundaries between individual and organizational levels are not always broken down, and these studies are not clearly framed in a consistent and unified theory.

Efforts made to examine entrepreneurship at various analytical levels, combining various ontologies and epistemologies derived from different disciplines (such as sociology and economics), have led to claims that the field lacks consistency and legitimacy (West 2003). Although bringing together perspectives from different fields is a unique source of new paradigms and stimulates innovation, experience in entrepreneurship research has shown that the fusion of approaches from different fields in a new entrepreneurship theory may lead to the field 
becoming an increasingly contested ground, rather than one generating consensus (Schindehutte and Morris 2009).

Over two decades have elapsed since the Low and MacMillan's recommendation (1988:

152) and no predominant and clear-cut theoretical paradigm or dominant theory stands out regarding the joint firm and individual level in the entrepreneurship research panorama.

This paper is structured as follows: epigraph 2 is an overview of the evolution of the individual level research; epigraph 3 reviews new individual approaches; epigraph 4 analyzes possible methods for the extension of entrepreneurship research to the organizational level. Epigraph 4 is a discussion about the suitability of the RBV and network-based theory for dealing with the most important business context variables. Finally, conclusions and perspectives for the future of research in the field are presented in epigraph 5.

\section{Individual Level Research Evolution}

\section{Entrepreneur's environmental conditions}

Some scholars have focused on the environmental conditions that may play a role in fostering entrepreneurship, paying attention to the overall economic, sociocultural, and political factors that influence people's willingness and ability to undertake entrepreneurial activities. Gnyawali and Fogel (1994) classify the literature on entrepreneurial environments into three broad areas: (a) general environmental conditions for entrepreneurship; (b) descriptive studies of the environmental conditions of a particular country or region; and (c) the role of public policy in shaping entrepreneurial environments. Most of this literature belongs to the macroeconomic level, but some of these factors have also been studied at an individual level for their potential to unleash entrepreneurial activity. 
When the expectation of finding a job is low and aspirations are blocked, individuals may chose to go into business. Gartner (1988), however, agrees with the criticisms of this view expressed by Locke and Latham (1990), who argue that optimizing career outcomes and low opportunity costs are not the key elements determining the perception of opportunities that lead to the creation of new firms. According to these authors many entrepreneurs do not fight shy when confronted with high opportunity costs and challenging objectives. On the contrary, these often motivate them to come up with innovative solutions to overcome obstacles. Although some environmental conditions like the one discussed may be included in a micro level analysis as individual circumstances, the lack of a conceptual framework integrating work on entrepreneurial environments advises against their inclusion in the microlevel analysis in an isolated manner.

\section{Entrepreneur's personal characteristics}

The idea that the entrepreneur is in some way different from the rest of the population was a powerful notion driving research in the 60 s and 70s. During this period the personality of entrepreneurs was emphasized and their risk taking propensity and ambition were seen as key features. The results of the work carried out, however, were discouraging (Low and MacMillan 1988). Interest in the entrepreneur's personal features persisted, nevertheless, through the 80s and to a lesser degree into the 90s. The underlying idea in these studies was that entrepreneurs belong to a homogeneous group with unique combination of characteristics that set them apart from the rest of society. These studies, however, were incapable of identifying consistent differences between entrepreneurs and non-entrepreneurs. Some of the factors whose implications were investigated were: parents' jobs, gender, race/ethnic group, education and 
work experience, psychological profile (Gartner 1988), age, risk taking propensity, attributes, attitudes, and values, internal locus of control, need for affiliation, extraversion and need of achievement; but the results obtained did not reveal any clear patterns.

The lack of explanatory power of these factors could lead to the conclusion that there is no special set of traits that is exclusive to entrepreneurs. But in spite of all these negative results, entrepreneurs and professionals keep considering the traits of the person that starts a firm the most critical factor for success. Therefore, the vision of business people differs considerably from the academic results obtained with this straightforward approach. This conflict has lead to new approaches in the study on firm creation and success. The need to understand and foster entrepreneurship makes it necessary to move beyond the mere description of entrepreneurs in order to inquire about the meaning of their decisions and establish a theoretical link in their behavior (Mitchell et al. 2002).

\section{New Individual Approaches}

The classification of the entrepreneurs by psychological traits having produced poor results, other lines of inquiry, such as the sociodemographic classifications proposed in the 90s, have also been dropped due to their low explicative power. This deadlock has favored the emergence of new approaches tackling the entrepreneurial function from an internal process point of view and yielding better results. Three lines of research are considered particularly relevant in this study, as they address notions of organizational behavior and management. 


\section{Self-efficacy}

A theoretical approach that has yielded better results is the one that combines the individual value systems and the cognitive mechanism with the social context. This perspective makes use of planned behavior theory, which propounds the idea of self-efficacy (Stajkovic and Luthans 1997) as developed in the organizational behavior literature, which considers that perceptions of desirability and feasibility are important for explaining intentions. Consider that individuals are more likely to follow the entrepreneurial path if they believe that they possess abilities required for success. Self-efficacy is the self-perception of the capacity needed to reach a desired performance level. Individuals gradually accumulate self-efficacy through cognitive, social and physical experiences.

Self-efficacy affects thinking patterns, improving or hindering performance depending on the results of past experiences. Before the concept of self-efficacy was applied to entrepreneurship, a positive relationship was established between motivation and individual performance, but it was not until the 90 s when entrepreneurship researchers incorporated the concept. There is a close relationship between entrepreneurial self-efficacy and the commitment to new ventures, actions and intentions. In fact, entrepreneurial self-efficacy is an important precedent for entrepreneurial intentions (Zhao et al. 2005). Most of the time, the role of the entrepreneur is not clearly defined, and there may be much uncertainty about the survival the newly created firm.

For the purposes of this study, entrepreneurial self-efficacy is especially relevant, as it incorporates personality as well as environmental factors. The key assumption is that the rate of individuals that become entrepreneurs is a function of their personal traits, their socioeconomic circumstances and the perception of the likelihood of the new ventures' success; this explains 
entrepreneurship by means of a positive feedback function. Self-efficacy is a complex construct, comprising several dimensions (McGee et al. 2009), and may include concepts developed in the following theories applied in individual level analysis.

\section{Behavioral and cognitive factors in entrepreneurship}

This view is based on the psychological uniqueness of the entrepreneur, but in this case the entrepreneurial function is studied as a process, thus overcoming the limitations found in previous entrepreneur' traits approaches. Taking cognitive psychology theory as a starting point, Baron (2009) proposes that cognitive mechanisms which model different styles of information processing can be linked to entrepreneurial actions. By incorporating the economic and managerial concept of information asymmetries to the entrepreneur's cognitive model, it is argued that information differences derive not only from differences in external source and context, but from the differences between the individuals processing information and the way they manage their own knowledge. Baron (2009) supports this assumption empirically and suggests that entrepreneurial success is closely linked to how the entrepreneur perceives and processes information. Information processing could also be relevant to prior research on personality and behavior.

This view assumes that the entrepreneur is prone to think in a particular way and that understanding it is essential for explaining their decisions to go on new ventures. Therefore, entrepreneurship research must address the entrepreneur's cognitive process, but also link it with context, circumstances, and environmental factors. In this approach the entrepreneur is studied as a decision maker, whose features throughout the process are the subject of inquiry. In this sense, 
some studies have confirmed that entrepreneurs use more heuristic thinking processes more extensively than CEOs.

Entrepreneurs tend to think by intuitive leaps from one set of concepts to another, whereas CEOs tend to engage more in critical thinking with its step-by-step deductive process. The heuristic type is more prone to generate innovative ideas that need not be based on lineal or factual thinking (Wright et al. 2000). Due to the high levels of ambiguity and uncertainty facing entrepreneurs in their search for new ventures, willpower and confidence in their heuristically made decisions, derived from very limited information, is sometimes the only way of progressing. In business contexts decisions are always complex and heuristics can be very helpful for taking best advantage of opportunities. The downside of this mindset is the high failure rate.

\section{Entrepreneurial function as a process}

Shook et al. (2003) understand the individual entrepreneurial function as an integrated process, which they break down into four phases: interacting with their environment (entrepreneurial intent), discovering, evaluating and exploiting opportunities. Here, the perspective change relative to prior research is considerable, since attention shifts from the entrepreneurs' personality traits and characteristics towards understanding the relationship between enterprising individuals and valuable opportunities (Shane and Venkataraman 2000). At the same time, this view is able to integrate what is most valuable in previous theories. When studying entrepreneurial intent Shook et al. (2003) emphasize the role played by the entrepreneur's psychological features (Mitchell et al. 2002). This first phase of the entrepreneurial process may be studied through the model of entrepreneurial intention (Henley 
2007) and the theory of planned behavior, analyzing the psychological, demographic or cognitive variables that make individuals have a natural bias toward new venture creation.

In the phase of opportunity discovering, research highlights the individual characteristics affecting decision-making (Baron 2009), information processing (West 2003) and strategic entrepreneurship (Baron 2009). In relation to the evaluation of new business opportunities, studies inquiring into the entrepreneurs' risk-taking propensity, motives and attitudes (Caliendo et al. 2009) are of special relevance. Lastly, studying opportunities exploitation involves concepts such as locus of control and self-efficacy (Rauch and Frese 2007).

This four-fold vision of entrepreneurship as a process integrates most of the recent advances in entrepreneurship research, moving forward from an isolated view of the entrepreneur to a deeper understanding of the context through the concept of opportunity in the entrepreneurial process. The good results obtained with this approach confirm the importance of personality and psychological traits in entrepreneurs; but these must be placed in a more complex, refined and multi dimensional model, moving beyond the mere description of unconnected traits. Cognitive psychology and planned behavior have played a decisive role in these models and some light has been shed on the role of general psychological characteristics by the meta-analysis carried out by Rauch and Frese (2007), which established a relationship, albeit a moderate one, between business owners' personalities traits and business creation and success.

The significance of the relationship has the same degree of importance as personality and performance in general, allowing the authors dismiss the idea that personality traits are not important in entrepreneurship research. Nevertheless, when the traits studied are more specific to new venture creation, such as self-efficacy, their relevance is considerable. The concept of selfefficacy is complex and multidimensional, and could be widened to incorporate the whole notion 
of process, as McGee et al. (2009) do in their application of the self-efficacy concept by dividing the construct into four phases: (1) searching, (2) planning, (3) marshalling, and (4) implementing (Mueller and Goic 2003).

\section{Broadening The Individual Level Analysis With The Inclusion Of The Business Context}

The latest results yielded by individual level research applying the most comprehensive theoretical frameworks have been promising. The entrepreneurial process approach (Shook et al. 2003) allows for the incorporation of managerial concepts such as entrepreneurial strategy, innovation or dynamic capabilities, although not always in a manner that avoids clashes and epistemological problems (West 2003; Schindehutte and Morris 2009). These studies, however, are essentially individual level analysis. The inclusion of managerial concepts (Rodriguez et al. 2010) is subordinated to the assessment of the individual personality and way of thinking, as organizational learning connects directly to the cognitive approach and heuristics, dominant in the entrepreneur's thinking, is close to the double-loop learning, new opportunities perception, quick learning and non-orthodox interpretations.

The learning process is also linked to the RBV and more specifically to the dynamic capabilities of Hamel and Prahalad (1994); but these dynamic capabilities are always included in entrepreneurship research as individual learning. Another area of management studies that can contribute to improve the cognitive models is innovation. The idea of entrepreneurship as a creative process is present in all approaches. Although it is dangerous to link invariably opportunity discovery and exploitation to innovation, there is no doubt that innovation and creativity are important elements in entrepreneurship. Creativity is closely connected to cognitive heuristics, and high learning and dynamic capabilities. In a similar way, strategic thinking is an 
essential component for detecting opportunities in a complex environment. Strategic

entrepreneurship is defined as the integration of entrepreneurial (opportunity seeking behavior) and strategic (advantage-seeking behavior) perspectives.

All these managerial approaches are enriching individual level entrepreneurship research, contributing depth and business significance, although not without clashes between approaches and difficulties regarding conceptual clarity, term confusion and theoretical hybridization (Schindehutte and Morris 2009). But the most valuable contributions all these managerial perspectives can make to entrepreneurship research are essentially on the individual level. Since the business context is introduced in a general way, and generally as a means of analyzing the mental processes associated to new venture development, rather than measuring business environment variables and establishing relationships with individual factors, the level of analysis remains fundamentally individual. The next step in research is to move to an organization level and include the business environment, not from a macro perspective, but to look into how it affects a specific entrepreneur. This will permit a better understanding of the causes of failure or success (Franco and Haase 2010) and help us come closer to a comprehensive predictive model of the entrepreneurial function. Two major management theories are considered for this purpose, the resource based view and the network theory.

\section{Entrepreneurship research from the resource based view}

The background created by the research on the cognitive processes of entrepreneurs has helped develop the resource-based view in the entrepreneurship field. This perspective can be used as a bridge between individual and firm levels of analysis in entrepreneurship studies. 
Since the beginning of RBV the entrepreneurial function has been recognized as part of the forces driving organizations and their capacities.

Entrepreneurship helps foster and combine resources, increasing heterogeneous resources and suggesting alternative uses of the latter. According to this approach, the business function is defined as the recognition and exploitation of economic profit-making opportunities.

Heterogeneity is a basic component of both RBV and business function theory. The underlying logic in RBV, however, has focused on the heterogeneity of the resources, while entrepreneurship theory has focused on the heterogeneity of beliefs surrounding resources values.

Two more key concepts enlarge the scope of RBV of entrepreneurship theory. The first one is the recognition of the entrepreneur, who is defined as the main actor in detecting new opportunities. The second concept refers to the entrepreneur's social capital, his way of understanding relationships with the other actors in his business, and the networks of contacts he develops. This concept also includes the social contexts within which new businesses are created. The entrepreneur's social networks help him obtain competitive advantage, and this makes understanding the processes of network creation, encouragement and upkeep essential (Fuentes et al. 2010; Fuller-Love 2009).

These two concepts are key for treating the process of combination and organization of resources as a capability of the firm. Accordingly, specific resources may reflect cognitive differences in the exploitation of resources between the managers of the firm.

The business function is understood as one of recognition of opportunities, from the individual level to the organizational capabilities of the firm. It makes sense in many activities such as the integration of resources or the ability to organize resources in the firm. 
Enterprising opportunities occur when different agents have different perceptions, and the agents take advantage of as yet unexploited opportunities. Dierickx and Cool (1989) focus on the importance of socially complex tacit assets. However, short literature has researched why these assets are created and exploited in order to created economical rents. Therefore, the firm function can be understood as the thinking out, discovery and search for new opportunities in the market, and the coordination of knowledge, resulting in heterogeneous processes, which are key to the RBV.

\section{Network-based research in entrepreneurship}

Approximately 20 years ago, research on networks emerged as an important new field within entrepreneurship studies. Following Hoang and Antoncic (2003) network-based entrepreneurship literature emphasizes: 1) network content (the nature of relationships and the access to resources they provide); 2) network governance (how networks and resource flows are coordinated); and 3) network structure (how relationships within networks are developed). These three components are the basis upon which theoretical models linking entrepreneurial activity and performance to networks are based.

Networks involve entrepreneurs at both the individual level and the firm level. Both types of entrepreneur make use of external networks comprising distributors, competitors, customers and suppliers among others. These networks allow the entrepreneur to access crucial tacit knowledge and other resources, as well as positioning within the social network. These relationships developed on the basis of common interest or common experience establishing and running businesses are extremely useful to entrepreneurs (Tolstoy 2010). 
One key element in the governance of the network is trust between its different members, which affects the depth and richness of relationships, particularly regarding information exchanges. In this sense, Pruitt (1981) holds that mutual trust as a governance mechanism is based on belief in a partner's reliability in terms of fulfilling the obligations involved in the exchange.

Network research within entrepreneurship attempts to explain the relationship between networks and entrepreneurial processes, how network structures are built, and what their consequences are. Some studies of the role of networks for entrepreneurship identify what kinds of ties are needed at varying stages of a firm's development. A holistic approach including both the structure of the network and interactions between actors appears, therefore, to be needed.

\section{Discussion}

There are a number of important variables involved in the success of a new venture which are mostly ignored by individual level analysis' ; amongst these are the entrepreneur's educational background, previous jobs, ownership of key assets, network of possible clients, suppliers and partners, etc. These variables, although quite different in nature, share a common feature: their intrinsic value depends on the industry or business area in which the new venture is launched. This implies that such variables must be assessed in relation to specific contexts, and that some parameters explaining how new ventures adapt to their environment are necessary.

In future, entrepreneurial research should include organizational variables in the individual level analysis in order to better explain performance differentials among new ventures (which requires some solid theoretical grounding). The RBV offers a theoretical framework in which entrepreneurs' individual capabilities like technical and business knowledge, ownership of 
scarce assets, fund access or innovation patents, and entrepreneurs' social capital and social networks can be analyzed. To explain the chances of success of a new business, these resources and capabilities, although some of them are individual, must be assessed from an organizational and industry perspective. The essential determinant of long-term survival and of economic profitability is the ability to accumulate, protect and continually develop resources and capacities that are valuable, rare, idiosyncratic, inimitable and that have imperfectly mobile (Grant 1991). The core assumption of the RBV understands the firm as a set of productive assets, whose value for firm growth does not lie in the assets themselves, but rather in the services they produce, or in the way they are used. It is recognized that knowledge is a resource that provides great added value to a business.

The theoretical framework of the RBV can be used to establish consistently relationships between contextual variables and individual characteristics, such as the fit of the entrepreneur's knowledge to the business context. Although in the study of knowledge as a source of competitive advantage from an organizational RBV the stress is put on tacit collective knowledge, in start-ups the entrepreneur's individual knowledge is the most valuable resource, in particular from the management and operational point of view, and even more so from a strategic perspective. In this last case, knowledge accounts for the capacity to design strategies that generate monetary value. In this case, the boundaries of the RBV are extended to include the cognitive ability of individual entrepreneurs. Concepts like previous jobs, experience, background, studies, etc., are essential to this kind of analysis, but they must be assessed by comparing them with competitor's and their fit to the specific needs of the entrepreneur's new business venture. 
As regards the entrepreneur's knowledge, the RBV can provide all the theoretical scaffolding necessary for its adequate treatment. Nevertheless, for other complex resources and capabilities, the assistance of additional complementary theories is necessary; as is the case with network theory for dealing with social capital. Social capital is another important factor that researchers are recurrently highlighting in entrepreneurship research (Westlund and Bolton 2003). Social or relational capital includes all knowledge assets accumulated by the entrepreneur from their relationships with other agents in the same environment.

This concept derives from the initial notion of customer capital, which was amplified to take into account the knowledge obtained through all kind of relationships with competitors, suppliers, associations, government, or other organizations that interact in the organizational environment. Social capital is related with legitimacy (Zimmerman and Zeitz 2002), which aids the survival of the new venture by providing credibility, contact, and support for the entrepreneur. Social capital is an asset available to individual or collective actors that draws on these actors' positions in a social network and/or the content of these actors' social relations' (Bratkovic et al. 2009). Networks are essential for acquiring other resources such as funding, partners, qualified personnel, technology, clients and suppliers. Furthermore, networks are valuable sources of information. According to Bowman and Ambrosini (2000), analytical procedures require excellent information on competitors, markets, customers and the internal position of the firm. Unfortunately, the required quality of information is rarely available for new entrepreneurs, and this can affect results negatively. 


\section{Conclusions and Future Research}

Entrepreneurship research has progressed considerably over the last three decades. After the failure of the first exploratory attempts in the 1980s, which attempted to link entrepreneurial behavior to simple individual characteristics and traits, the need for a sound theoretical framework to ground entrepreneurial research became evident. Reality proved more complex than expected (Low and MacMillan 1988) and it has been all the power of the cognitive theory has been required to create more abstract and comprehensive constructs such as self-efficacy to cope with the problem. The cognitive model plays a determinant role in understanding all the phases of the entrepreneurial process (Shook et al. 2003) and is the cohesive element that permits the inclusion of managerial approaches in individual level analysis in entrepreneurship research. The natural extension of the successful individual cognitive theories to the realm of management, using management concepts for each entrepreneurial process phase, rather than combining or merging existing theories, is likely to be the approach that will yield the best results in the near future.

Although great progress has been made in this field, it is still necessary to deepen our knowledge of the cognitive model and build reliable measurement tools that allow us validate different explanatory models (McGee et al. 2009). This kind of research requires the collaboration of multidisciplinary teams in cognitive psychology and management. If so far research has been able to answer the questions of who is more prone to become an entrepreneur and how they behave in the different phases of the creation of a new business, the following question that must be answered is why only some entrepreneurs succeed and so many fail. Answering this question requires incorporating the environment, but not merely as the general context facing the entrepreneur and analyzing the kind of problems found in it, but also 
viewing it as a competitive business context. To tackle this problem the RBV is perhaps the most suitable and comprehensive managerial framework.

The RBV tries to explain abnormal profits from the resources and capacities of organizations in comparison with their competitors. The RBV is a general approach capable of incorporating the most relevant organizational factors as highlight by the entrepreneurship literature; such as the entrepreneur's social and educational background, work experience, ownership of assets and patents, social capital, etc. This general approach can be complemented by other managerial theories dealing with complex resources, such as, for example, network theories. It must nevertheless be born in mind that some perspectives can only be complementary, no matter how relevant they be to the entrepreneurial function. For instance, it is essential to know the rate of new business ventures based on innovation, or what percentage of start-ups have an innovation at the core of their creation, and if new ventures are essentially more innovative than well-established firms. But an exclusive vision of entrepreneurship as innovation would be partial and limited, as innovation is not the essence of entrepreneurship, for it is opportunity grasping that really lies at its core. At the same time, denying a role to innovation in an organizational level framework would subtract explanatory power from the entrepreneurship model. 


\section{References}

Auerswald, P. (2008). Entrepreneurship in the theory of the firm. Small Business Economics, 30(2), 111-126.

Baron, R. A. (2009). Effectual versus predictive logics in entrepreneurial decision making: differences between experts and novices: does experience in starting new ventures change the way entrepreneurs think? Perhaps, but for now, "Caution" is essential. Journal of Business Venturing, 24(4), 310-315.

Bowman, C., \& Ambrosini, V. (2000). Value creation versus value capture: towards a coherent definition of value in strategy. British Journal of Management, 11(1), 1-15.

Bratkovic, T., Antoncic, B., \& Ruzzier, M. (2009). Strategic utilization of entrepreneur's resource-based social capital and small firm growth. Journal of Management and Organization, 15(4), 486-499.

Caliendo, M., Fossen, F., \& Kritikos, A. (2009). Risk attitudes of nascent entrepreneurs-new evidence from an experimentally validated survey. Small Business Economics, 32(2), 153-167.

Chiles, T. H., Vulture, D. M., Gupta, V. K., Greening, D. W., \& Tuggle, C. S. (2010). The philosophical foundations of a radical Austrian approach to entrepreneurship. Journal of Management Inquiry, 19 (2), 138-164.

Davidsson, P., \& Wiklund, J. (2001). Levels of analysis in entrepreneurship research: current research practice and suggestions for the future. Entrepreneurship: Theory \& Practice, 6(2), 81-99. 
Davidsson, P., Delmar, F., \& Wiklund, J. (2006). Entrepreneurship as growth; growth as entrepreneurship. In P. Davidsson, F. Delmar, \& J. Wiklund (Eds.), Entrepreneurship and the growth of firms (pp. 21-38). Cheltenham: Edward Elgar Publisher.

Dierickx, I., \& Cool, K. (1989). Asset stock accumulation and sustainability of competitive advantage. Management Science, 35(12), 1504-1511.

Franco, M., \& Haase, H. (2010). Failure factors in small and medium-sized enterprises: qualitative study from an attributional perspective. International Entrepreneurship and Management Journal, 6(4), 503-521.

Fuentes, M., Ruiz, M., Bojica, A., \& Fernandez, V. (2010). Prior knowledge and social networks in the exploitation of entrepreneurial opportunities. International Entrepreneurship and Management Journal, 6(4), 481-501.

Fuller-Love, N. (2009). Formal and informal networks in small businesses in the media industry. International Entrepreneurship and Management Journal, 5(3), 271-284.

Gartner, W. B. (1988). Who is the entrepreneur? Is the wrong question. American Journal of Business, 12 (14), 11-32.

Gnyawali, D. R., \& Fogel, D. S. (1994). Environments for entrepreneurship development: key dimensions and research implications. Entrepreneurship: Theory and Practice, 18(4), 4362.

Grant, R. M. (1991). The resource-based theory of competitive advantage: implications for strategy formulation. California Management Review, 33(3), 114-135.

Hamel, G., \& Prahalad, C. K. (1994). Competing for the future. Boston: Harvard Business School Press. 
Henley, A. (2007). Entrepreneurial aspiration and transition into self-employment: evidence from British longitudinal data. Entrepreneurship \& Regional Development, 19(3), 253280.

Hoang, H., \& Antoncic, B. (2003). Network-based research in entrepreneurship: a critical review. Journal of Business Venturing, 18(2), 165-187.

Locke, E. A., \& Latham, G. P. (1990). A theory of goal setting and task performance. Englewood Cliffs: Prentice Hall.

Low, M. B., \& MacMillan, I. C. (1988). Entrepreneurship: past research and future challenges. Journal of Management, 14(2), 139-161.

McGee, J. E., Peterson, M., Mueller, S. L., \& Sequeira, J. M. (2009). Entrepreneurial selfefficacy: refining the measure. Entrepreneurship: Theory \& Practice, 33(4), 965-988.

Mitchell, R. K., Busenitz, L., Lant, T., McDougall, P. P., Morse, E. A., \& Smith, J. B. (2002). Toward a theory of entrepreneurial cognition: rethinking the people side of entrepreneurship research. Entrepreneurship: Theory \& Practice, 27(2), 93-104.

Mueller, S. L., \& Goic, S. (2003). East-West differences in entrepreneurial self-efficacy: implications for entrepreneurship education in transition economies. International Journal of Entrepreneurship Education, 1(4), 613-632.

Pruitt, D. G. (1981). Negotiation behavior. New York: Academic.

Rauch, A., \& Frese, M. (2007). Let's put the person back into entrepreneurship research: a metaanalysis on the relationship between business owners' personality traits, business creation, and success. European Journal of Work and Organizational Psychology, 16(4), $353-385$. 
Rodriguez, A., Rodriguez, A., \& Murillo, G. (2010). New perspectives for the managerial entrepreneurship. International Entrepreneurship and Management Journal, 6(2), 203219.

Schindehutte, M., \& Morris, M. H. (2009). Advancing strategic entrepreneurship research: the role of complexity science in shifting the paradigm. Entrepreneurship: Theory \& Practice, 33(1), 241-276.

Shane, S., \& Venkataraman, S. (2000). The promise of entrepreneurship as a field of research. Academy of Management Review, 25(1), 217-226.

Shook, C. L., Priem, R. L., \& McGee, J. E. (2003). Venture creation and the enterprising individual: a review and synthesis. Journal of Management, 29(3), 379-399.

Stajkovic, A. D., \& Luthans, F. (1997). A meta-analysis of the effects of organizational behavior modification on task performance, 1975-95. Academy of Management Journal, 40(5), 1122-1149.

Thurik, A. R., \& Wennekers, A. (2004). Entrepreneurship, small business and economic growth. Journal of Small Business and Enterprise Development, 11(1), 140-149.

Tolstoy, D. (2010). Knowledge combination in networks: evidence from the international venturing of four small biotech firms. International Entrepreneurship and Management Journal, 6(2), 183-202.

van Stel, A. J. (2006). Empirical analysis of entrepreneurship and economic growth (International studies in entrepreneurship series, vol. 13). New York: Springer Science.

Veciana, J. M., \& Urbano, D. (2008). The institutional approach to entrepreneurship research. Introduction. International Entrepreneurship and Management Journal, 4(4), 365-379. 
Welter, F., \& Lasch, F. (2008). Entrepreneurship research in Europe: taking stock and looking forward. Entrepreneurship: Theory \& Practice, 32(2), 241-248.

West, G. P., III. (2003). Connecting levels of analysis in entrepreneurship research: a focus on information processing, asymmetric knowledge and networks. In C. Steyaert \& D. Hjorth (Eds.), New movements in entrepreneurship (pp. 51-70). London: Edward Elgar.

Westhead, P. (2008). Entrepreneurship: concepts, theory and perspectives. International Small Business Journal, 26(2), 251-255.

Westlund, H., \& Bolton, R. (2003). Local social capital and entrepreneurship. Small Business Economics, 21(2), 77-113.

Wright, M., Hoskisson, R. E., Busenitz, L. W., \& Dial, J. (2000). Entrepreneurial growth through privatizations: the upside of management buyouts. Academy of Management Review, 25(3), 591-601.

Zhao, H., Seibert, C., \& Hills, C. (2005). The mediating role of self-efficacy in the development of entrepreneurial intentions. Journal of Applied Psychology, 90(2), 1265-1272.

Zimmerman, M. A., \& Zeitz, G. J. (2002). Beyond survival: achieving new venture growth by building legitimacy. Academy of Management Review, 27(3), 414-431. 